\title{
Interactive Vision and Experimental Traditions: How to Frame the Relationship*
}

\author{
Anna Estany \\ Departamento de Filosofía, Universidad Autónoma de Barcelona (UAB), Barcelona, Spain \\ Email: anna.estany@uab.cat
}

Received December $17^{\text {th }}, 2012$; revised January $18^{\text {th }}$, 2013; accepted February $3^{\text {rd }}, 2013$

\begin{abstract}
Copyright (c) 2013 Anna Estany. This is an open access article distributed under the Creative Commons Attribution License, which permits unrestricted use, distribution, and reproduction in any medium, provided the original work is properly cited.
\end{abstract}

\begin{abstract}
In recent decades, the cognitive view has had a considerable impact on the philosophy of science, and two reasons can for this be identified. First, philosophers have increasingly tended towards naturalistic approaches, as opposed to proposals that are more a priori. Second, the cognitive sciences underwent considerable development in the second half of the twentieth century. Motivated by the cognitive view in the philosophy of science, and within a naturalistic framework, the aim of this paper is to analyze the relationship between two pairs of views. On the one hand, I consider the theoretical and experimental traditions; and on the other, I examine the views of pure and interactive vision. The two pairs belong to two independent debates; one in the philosophy of science (theoretical vs. experimental traditions) and the other in cognitive psychology (pure vs. interactive vision). Theoretical traditions correspond to a conception of science according to which the goal of scientific practice is to formulate theories that represent the world, and in them experiments play only an instrumental role that is always subsidiary to theory. The model of science promoted in the program of logical empiricism is a good example of such a tradition. Experimental traditions, in contrast, challenge that conception of science by attributing a more important role to experimentation, which is said to provide its own path to knowledge.
\end{abstract}

Keywords: Interactive Vision; Motor Representations; Experimental Traditions

\section{Introduction}

In recent decades the cognitive view has had an impact on the philosophy of science that it is important to take into account. We can identify two reasons for this which, if not the only ones, are certainly important. One is the project of naturalizing philosophy that more and more philosophers have adopted in contrast to a style of philosophy that is more concerned with the a priori. The other is the considerable development that the cognitive sciences underwent throughout the second half of the 20th century.

Within the framework of the naturalization of philosophy from a cognitive point of view, the objective of this paper is to analyze the relation between, on the one hand, theoretical and experimental traditions (ET); and, on the other, the conceptions of pure vision and of interactive vision. Such a relation could exist in a number of different ways:

- The first member of each pair could mutually reinforce each other; that is, the theoretical traditions (TT) provide arguments in favor of pure vision and such reinforcement also occurs in the opposite direction.

\footnotetext{
${ }^{\mathrm{j}^{*}}$ Financial support for this research was received from the Spanish Government's DGICYT research project: FFI2011-23238, “Innovation in scientific practice: cognitive approaches and their philosophical consequences”. I am grateful to Edwin Hutchins for his support when I was visiting scholar in University of California, San Diego. I am also grateful to Peter Gardenfors to suggest me the possible relationship between interactive vision and experimental traditions after my contribution in the 9th International Congress of Logic, Methodology and Philosophy of Science (Uppsala, 1991).
}

- The same could happen but between ET and interactive vision (in both directions).

- The members of the two pairs could be irrelevant to each other, in both of the above senses.

The working hypothesis with which I set out is that a parallel can be drawn between TT and pure vision; and also between ET and interactive vision. Starting from this thesis, we will see some of the consequences for certain emblematic issues in the philosophy of science, particularly for the relationship between theory and experiment. At the same time, the relation between interactive vision and ET will lead us to take into account the connection between the visual system and the motor system; an idea that goes back to P. S. Churchland, V. S. Ramachandran and T. J. Sejnowski (1994) “A Critique of Pure Vision”, but which has been supported by more recent research.

The point is that there are two debates which, to a great extent, have taken place independently; one in the philosophy of science (TT versus ET) and the other in the cognitive psychology (pure vision versus interactive vision). TT correspond to a conception of science in which the objective of scientific research is to formulate theories that represent the world and according to which experiments have a purely instrumental character, or at least they are subsidiary to theory. The model of science endorsed by logical empiricism is a good representative of TT. In contrast, ET question such a model of science and attribute a more important role to experimentation, which is seen as providing its own means of consolidating knowledge.

On the other side of the relationship, in the field of the cogni- 
tive sciences, there is a debate concerning visual perception that takes place in terms of pure vision versus interactive vision. The idea of pure vision was proposed by D. Marr (1982) in "Vision". Marr considers that what we see when we contemplate something is a complete elaboration of the visual scene. The idea of interactive vision is defended by P. S. Churchland, V. S. Ramachandran and T. J. Sejnowski (1994), among others, who consider that pure vision is a fiction and that what we see at a given moment is only a partially elaborated representation of the visual scene. Referring to the connection between the visual and motor realms, Churchland et al. maintain that: "The anatomy is consistent with the idea that motor assembly can begin even before sensory signals reach the highest levels. Especially for skilled actions performed in a familiar context, such as reading aloud, shooting a basket, and hunting prey, this seems reasonable” (Churchland et al., 1994: p. 43).

The independence of these two debates should be understood in the sense that no links have been established that relate the two approaches. ET are sometimes related to the development of Kuhnian and post-Kuhnian philosophy of science and are therefore seen as a result of our philosophy of science moving away from a logicalist and rationalist approach and towards dominance of historicist and sociological approaches. However, there are differences that are too important between the different post-Kuhnian approaches for ET to be considered a straightforward evolution from those approaches. In addition, there is the cognitive element which has always remained very much in the background in the majority of work in post-Kuhnian philosophy, which is much more focused on the historical and sociological elements.

I will begin by examining the differences between the conception of pure vision (Marr) and that of interactive vision (Churchland, Ramachandran, \& Sejnowski). The latter is connected to the motor system and as a consequence motor representations acquire particular importance. Secondly, I will analyze the main theses of a philosophy of science that focuses on ET and contrast them with a philosophy of science that is centered on TT, in the light of the models of pure and interactive vision. Finally, I will consider the consequences of this analysis for the relation between theory and experiment, and how that relation can have repercussions for what we understand by representations of knowledge.

\section{From Interactive Vision to the Motor System}

The 1994 paper by Churchland, Ramachandran and Sejnowski is a landmark in the revision of Marr's model of pure vision (1982) and in the defense of interactive vision. The characterization that the authors attribute to pure vision can be summarized by the following points:

What we see at any given moment is in general a fully elaborated representation of a visual scene; signal elaboration is a hierarchical process; higher levels in the processing hierarchy depend on lower levels, but not, in general, vice versa (Churchland et al., 1994: p. 25).

In contrast, they attribute interactive vision with the following characteristics:

The visual system of the brain has the organization, computational profile, and architecture for feeding, fleeing, fighting and reproduction; what we see at any given mo- ment is a partially elaborated representation of the visual scene and only relevant information is represented; the interactive vision is exploratory and predictive; an interactive vision will suggest that motor assembling begins on the basis of preliminary and minimal analysis; new research challenges the conventional conception of a chiefly unidirectional, low-to-high processing hierarchy; rich recurrence in network processing also means that stored information from early learning plays a role in what the animal literally sees; and if the visual system is intimately and multifariously integrated with other functions, including motor control, approaching vision from the perspective of sensorimotor representation and computations may be strategically unavoidable (Churchland et al., 1994: pp. 26-28).

Although vision has been the centre of the discussion of whether perception in general is pure or interactive, it is important not to undervalue research into other senses, in particular hearing, as M. Slaney (1998) indicates when applying the analysis of Churchland, Ramachandran and Sejnowski to audition. Slaney refers to a series of experiments from which it can be deduced that recent experience can influence the sounds that we perceive; a demonstration that there are auditive systems that use information in a top-down manner. In fact, it indicates that we perceive the voice of someone speaking a language that we have never heard before as just a source of sound and not as isolated tones. Furthermore, it shows that it is the possibility of top-down auditory processes that allows us to distinguish speech in a noisy environment. However, Slaney recognizes that, for the moment, it is not easy to design and experimentally test top-down cognitive processes and interactive systems.

Taking into account the objective of this paper, which is to explore the possible connection between ET and interactive vision, it is logical that of all the perceptive systems I focus on vision and, very particularly, on the relation between interactive vision and the motor system. One of the reasons for the relevance of the motor system to the subject I am concerned with here is that it is related, at least from the perspective of interactive vision, with action. Therefore, the connection between interactive vision and the motor system seems evident.

With regard to this question, the classic scheme is the following: first perception, then cognition and, finally, movement. This scheme seemed perfectly convincing while the image that dominated our understanding of the motor system was a simplified one but, as Rizzolatti and Sinigaglia (2006) point out, the motor system has to do with action and not merely with movement. It is in our actions that our experience of the environment that surrounds us becomes important and where things gain meaning. Thus we can say that: "the acting brain is also and above all a brain that understands" but we are talking of "a pragmatic, pre-conceptual and pre-linguistic form of understanding, but it is not less important for that, because it lies at the base of many of our celebrated cognitive abilities" (Rizzolatti \& Sinigaglia, 2006: p. xi).

Based on neurological research it can be seen that: "not only is the motor system connected anatomically to the cortical areas responsible for the cerebral activity involved in 'thought and sensation', but it also has a plurality of functions that are not compatible with the concept of a sole, purely executive map" (Rizzolatti \& Sinigaglia, 2006: p. 8). The fact that sensorial and motor information can be redirected into a common format, 
codified by specific parietofrontal circuits, suggests that, beyond the organization of our motor behavior, certain processes generally considered to be higher order and attributed to cognitive-type systems (such as for example perception and recognition of the actions of others, imitation and vocal or gestural forms of communication) can also be directed to the motor system and encounter in it their own primary neural substrate (Rizzolatti \& Sinigaglia, 2006: p. 20).

In this theoretical framework "mirror neurons", also studied by Rizzolatti and Sinigaglia (2006), take on a special relevance. The research by Rizzolatti and Sinigaglia on monkeys demonstrated that mirror neurons reacted both when the monkey performed a specific action (such a grabbing food) and when the monkey observed another individual (the experimenter) perform a similar action. These discoveries immediately suggested that there may be something similar in humans. The conclusion was that humans possess "mirror properties" although with some differences compared to those of monkeys. Human mirror neurons can codify both the objective of the motor act and also the temporal aspects of each one of the movements that comprise the act, and these differences have an important functional significance (Rizzolatti \& Sinigaglia, 2006: pp. 116-118). Just as with the monkey, in people the sight of acts performed by others establishes in the observer an immediate involvement of the motor areas dedicated to the organization and execution of those actions. Furthermore, just as with the monkey, in people that involvement allows the "meaning" of the observed "motor events" to be deciphered, that is, to "understand them" in terms of actions. This understanding simply appears without any reflexive, conceptual or linguistic contemplation, as it is based solely on the "vocabulary of acts" and on the "motor knowledge" on which our characteristic capacity to act depends. (Rizzolatti \& Sinigaglia, 2006: p. 125).

I will analyze the relevance of this research for scientific practice below. For now, I wish to point out, on the one hand, the link between interactive vision and the motor system, which is focused on action; and on the other, the fact that mirror neurons cause the motor system to react not only through performing an action but also through the observation of an action. If, with this idea in mind, we consider laboratory work, we can say that observing how an experiment is carried out implies that the motor systems of the scientists who observe react; possibly not to the same extent as the motor system of the person who performs the action, but sufficiently for us to be able to consider it cognitive reinforcing. It could be objected that according to TT, scientists also perform experiments; but the importance and the meaning attributed to them is secondary compared to theory and, particularly, no importance is given to the observation of experiments that are performed by others.

All of this leads us to motor cognition, which has been widely studied, among others by Marc Jeannerod (2006) in his seminal work Motor cognition. What actions tell the self. His contribution is particularly relevant to one of the problems that arises as a consequence of the relation between theory and experiment: the representations of action that Jeannerod considers to be the core of motor cognition.

\section{Theoretical Traditions versus Experimental Traditions}

The debate concerning the role of theory versus the role of experiment is an old one in the philosophy of science, and it has crystallized in the comparison between TT and TE. From the perspective of TT, the philosophy of science has fundamentally focused on theoretical models, on established laws and princeples, and ultimately on the reconstruction of scientific theories, leaving experimentation to play a secondary role. For the majority of schools, both the Received View (RV) and the Kuhnian vision of science, experimentation has depended on theory, whether through being inspired by it or because it is there to serve theory; but in any case, without a life of its own (Hacking, 1996) ${ }^{1}$. In accordance with this conception of science, experimentation is considered to be a way of verifying theories, just as it was seen in the logical empiricism of C. Hempel, or as a way of falsifying theories from a Popperian point of view. Both historians and philosophers have argued against this approach in the philosophy of science by maintaining that experimentation should occupy a more central role. One of the most prominent of those philosophers is I. Hacking who, in his 1983 book Representing and Intervening defends the idea that philosophy should rejoin the task started in the 17th century and place experimentation at the centre of the scientific enterprise. M. Iglesias (2004) in turn refers to the importance of experimental practices to demonstrate the shift that is necessary in the philosophy of science and the change in the traditional relationship between theory and experiment. The shift towards practice in the philosophy of science means that the notions of rationality, objectivity, truth and the world are no longer only treated from a theoretical point of view and that new philosophical problems are defined, promoting a new image of science. This implies that we need to take into account other factors that intervene in the scientific project, such as the material infrastructure, instruments, human interaction, relations with the authorities, etc.

For philosophers and historians of science from the positivist school it was common to describe the processes of the elaboration of scientific theories as based on measurements and precise quantitative data, in which research referred to quantitative experiments. This simplified version of the scientific method completely removed qualitative experimentation from the picture (Ordoñez \& Ferreirós 2002). The new philosophers and historians reinstate a role for qualitative experiments and the effect they can have on the construction of knowledge. In this way, experimentation is moving away from the old tradition of being guided by theory, as K. Popper suggested it was in the first edition of "Logik der Forschung", in 1935: "the theoretician puts certain definite questions to the experimenter, and the latter by his experiments tries to elicit a decisive answer to these questions, and to no others" (Popper, 2002: p. 89). Instead, experimentation is gaining a life of its own, independent of theory. Despite the fact that Popper forms part of the TT insofar as he sees experimentation as being at the service of theory, his divergence from RV means that we cannot draw a direct parallel between his model of science and Marr's pure vision, as we

\footnotetext{
${ }^{1}$ At this point it is as well to make a distinction between Hempel and Kuhn (taken as representative of RV and of the historical approach, respectively). Both can be considered to be within TT insofar as they do not place experimentation at the center of scientific research. However, what they maintain is different in important ways with respect to the theory ladenness of observation. Thus, while Hempel bases the empiricist criterion of meaning on neutral observation, Kuhn considers that observation is conditioned by the paradigm from which it takes pale. The consequence is that Hempel's position fits in with pure vision, but that is not the case for Kuhn's position, even though it is not in agreement with interactive vision. See Estany (2001) for an analysis of the theory ladenness of observation from theories of perception.
} 
seem to be able to with RV.

Through case studies, philosophers of science aim to demonstrate the existence of an experimental ladenness of theory. This is the case of Hacking (1983); Galison (1987); Gooding, Pinch and Schaffer (1989); Pickering (1995); and Martinez (1995), among others, who move towards a new image of science. J. Ordoñez and J. Ferreirós (2002) consider that the misfortune of theoreticism resides in the way it reduces the wealth and complexity of scientific practice to a matter of mere conceptual elaboration leaving out the wealth of knowledge that lies behind experimental practices. Recognizing the importance and validity of experimental practice, its function independent of theory or in equilibrium with it, and its role beyond the one it is usually seen as having of merely verifying or falsifying, constitutes the basis of this approach to the philosophy of science.

Another aspect that is important in the philosophy of experimental practice is the type of discourse there is in the experimentation itself, which does not correspond with that which is assigned to deduction in RV. In experimentation there is a form of argumentation and of knowledge that is different from the phenomenon of deduction (Galison, 1987). It is necessary to recognize that in action there is thought, which means breaking with and overcoming the Cartesian dualism that separates mind and body, nature and culture. There is a different language that is expressed in experimental activity and which gives rise to thoughts and ideas that are later expressed conceptually.

Experimental knowledge is present in the design and building of apparatus, but also in the manipulation of artifacts and in the creation of phenomena. So we have to accept that in experimental activity there is a conceptual wealth that has not been recognized or valued as highly as it should have been. We need to bear in mind that in experimentation, as Iglesias suggests: "nature does not reveal herself to us on her own: she opens up, she unfolds, in keeping with the way in which she is subjected to a specific action” (Iglesias, 2004: p. 11).

Making experimentation a platform for knowledge contributes to a change in the image of science. The way to present experiments must not be solely descriptive or narrative reinforcing the role of theories. Instead we should move towards a characterization of experimentation that involves its own problems and that has a conceptual wealth of its own (a life of its own), create needs where the experiment "talks" and there is communication, create specific situations where nature "unfolds" and demonstrates certain behavior to us; that is, make experimentation a human activity. Case studies that show the role of experimentation in the framework of the philosophy of experimental practice allow us to identify valuable aspects of scientific activity that must be recognized and considered by philosophers of science.

\section{Cognitive Support for Experimental Traditions}

At the start of the paper I put forward as a working hypothesis the idea that cognitive models of vision are relevant to the philosophical models of science with respect to the relation between theory and experiment.

One of the important points for the distinction between pure and interactive vision is the classic hierarchical scheme, as shown in Scheme 1(a). In comparison to this scheme, we could put forward a reticular system which, among other things, would mean that motor assembly (referring to movement) begins after a minimum preliminary analysis. Scheme 1(b) shows such a reticular arrangement, in which the type of figure that best reflects this idea is the equilateral triangle ${ }^{2}$.

In addition, if we take onboard the conception of motor system that Rizzolatti and Sinigaglia put forward, the alternative to the classic scheme not only consists of moving from the hierarchical system to a reticular one, but also of substituting the idea of movement for that of action, as shown in Scheme 2, which includes an intervention of the intentions behind the motor act. These are what ultimately give meaning to the action.

What would the classic scheme of the scientific method be like from the perspective of TT, equivalent to that of pure vision? Scheme 3(a) represents the hierarchical scheme of TT, where experimentation is simply there to support theory. In contrast, in a reticular scheme, such as that shown in Scheme 3(b), it is not necessary for the experimental process to start with a hypothesis, rather the hypothesis could be just roughly laid out, in the same way in which motor assembly can begin with only a minimum analysis of the visual scene. In addition, although experiments do provide knowledge regarding the phenomena studied, they would not necessarily be devoted to the formulation of a theory in the same way as they are in RV.

There are still, however, several questions to clarify in the extrapolation from the cognitive framework to the methodological scheme. One of them is whether we can find something that is equivalent of the difference that Rizzolatti and Sinigaglia indicate between movement and action. The fundamental difference is that in an action, the end or goal plays a role; that is, we could define action as the sum of movements and ends. If we consider that the objective of science it to explain the material and social world, the equivalent of action could be scientific explanation.

One possibility would be that experiments are considered to be equivalent to movements in TT and to actions in TE. However, this would stretch the parallel too far. In TT, the objective of experiments is to test theories; although it is true that this is not the end in itself but rather depends on the theory, as mentioned.

Another important question is whether, independently of the hierarchical or reticular scheme, we can conceive of an experiment that has no intention or objectives. At least methodologically speaking, it is not possible; however, there are precedents in the philosophy of science of similar questions being asked. I have in mind C. G. Hempel's (1966) criticism of A. B. Wolfe (1924) regarding the stages of scientific research. Wolfe places data collection in the first stage of the process of hypothesis testing, which is a proposal that Hempel qualifies as "narrow inductivism" because he considers that the search for data makes no sense without a criterion regarding what is relevant to the hypothesis that we wish to test. In the same way, we could ask ourselves whether it is possible to design an experiment if we have no theory as a frame of reference. Wolfe's suggestion also follows a hierarchical scheme but places data collection first, as shown in Scheme 4(a). Hempel's position corresponds to Scheme 4(b).

Both in the reticular Scheme 3(b), and in Wolfe's proposal (Scheme 4(a)) we need to get around the problem of how to act if we have no guide: What data do I look for if I do not take my lead from a hypothesis? How can we design an experiment

${ }^{2}$ Laudan, in a different context, also proposes a reticular system as opposed to a hierarchical one to refer to the relation between facts, methods and values. 


\begin{tabular}{|l|}
\hline Perception \\
\hline Cognition \\
\hline Movement \\
\hline
\end{tabular}

(a)

\begin{tabular}{|l|c|}
\hline \multicolumn{2}{|c|}{ Perception } \\
\hline Cognition & Movement \\
\hline
\end{tabular}

(b)

Scheme 1

\begin{tabular}{|l|l|}
\hline \multicolumn{2}{|c|}{ Perception } \\
\hline Cognition & Action \\
\hline
\end{tabular}

Scheme 2

\begin{tabular}{|c|}
\hline Hipothesis \\
\hline Experiment \\
\hline Theory \\
\hline
\end{tabular}

(a)

\begin{tabular}{|l|l|}
\hline \multicolumn{2}{|c|}{ Hipothesis } \\
\hline Experiment & Theory \\
\hline
\end{tabular}

(b)

Scheme 3

\begin{tabular}{|c|}
\hline Data collection \\
\hline Hipothesis \\
\hline Experiment \\
\hline Theory \\
\hline
\end{tabular}

(a)

\begin{tabular}{|c|}
\hline Hipothesis \\
\hline Data collection \\
\hline Experiment \\
\hline Theory \\
\hline
\end{tabular}

(b)

Scheme 4

without a theoretical framework?

Two reflections are called for at this point:

- Interactive vision claims that motor assembly (and therefore, action) begins after only a preliminary and minimum analysis; that is, minimum but existent. By analogy, in scientific practice this would mean that theory could be minimum but existent. Therefore, it does not in any way assume experimentation taking place completely in the dark with no guide at all. That is why it is very important what type of relationship is established between theory and experimentation.
In fact, we can say that the weight of experiment and that of theory are not the same in all fields or at all stages of research.

- The objective or end of an action is important; in the case of the visual system, the end is to facilitate the development of the organism and, ultimately, the survival of the species. In the case of scientific practice, the objective is also key, whether it is the explanation of a phenomenon or the application of knowledge to resolving practical problems, as in the case of design sciences ${ }^{3}$.

One of the characteristics of interactive vision that Churchland, Ramachandran and Sejnowski point out is that the information stored from previous learning plays a role in what we see. So, we do not face the world with a tabula rasa but rather with cultural frameworks that affect what we perceive and how we act. Neither do scientists face the phenomena that they want to explain with a completely empty hand, but with a whole wealth of theoretical and practical knowledge acquired throughout the process of training, integration and socialization as a scientist. From the perspective of TT, it seems that this baggage would have to be limited to theoretical models; in contrast, ET incorporate practical learning and knowhow by way of patterns, norms of conduct or “heuristics” in Martínez's sense (2006).

Finally, there is a question that refers to the fact that the model of interactive vision considers the visual system to be made up of multiple functions and, consequently, it goes beyond the static representation of an image. We can compare this to the current conception in the philosophy of science that we should take into account all the factors that intervene in scientific research. This is where the term "philosophy of scientific practice" comes from, in the sense that practice implies taking account of much more than simply science as a product.

\section{The Conjunction of Experiment and Theory under the Prism of Interactive Vision}

One of the issues to be examined in the debate concerning TT and TE is the relation between theory and experiment. At the core of this question is the analysis of the elements that intervene in the interpretation of an experiment. In TT, meaning emerges from theory; in contrast to what happens in TE where it emerges from experiment. The most plausible hypothesis is that meaning emerges from the conjunction of both (theory and experiment). We will see to what extent the model of interactive vision supports such a conjunction.

The idea of convergence between theory and experiment leads us away from solutions that consist of reversing terms and attributing to experimentation the role that theory played in TT. Only the metaphor of the pendulum could explain that kind of decision. If the current work makes sense, it is because, even though TE may reflect scientific practices much better than TT (both historically and at present) and furthermore they do justice to the experimental work of many scientists, the alternative they offer is not simply to reverse roles, but to see in what terms we should establish the relation between theory and ex-

\footnotetext{
${ }^{3}$ The goal of design sciences is to transform the world and not only to describe it, as is the priority of pure or basic science such as physics, chemistry biology, psychology and sociology. Engineering, medicine, information science, the science of education, etc. are design sciences that result from applying scientific knowledge to solve practical problems. See SIMON, H. A., The science of the artificial, The MIT Press, Cambridge, MA, 3rd ed., 1996, and NIINILUOTO, I., "The aim and structure of applied research," Erkenntnis, 38, (1993), pp. 1-21.
} 
periment ${ }^{4}$.

Such a conjunction can be approached from different directions. One of them is the historical path, linked to the role of instruments and to debates surrounding scientific method. The history of science provides numerous cases that exemplify both the importance of instruments and the debates that have arisen regarding their role in the scientific method. Among many others, we can cite the following examples: the importance of the contribution of the chemists Priestley and Cavendish is beyond doubt, but the recognition they are afforded as scientists is not the same from TT as from TE, given that their theoretical framework was somewhere between the chemistry of phlogiston (Stahl) and Lavoisier's theory of combustion; the role that instruments such as the scales and the gasometer played in the chemistry revolution brought about by Lavoisier; the fact that the emergence of psychology as a science is linked to the experimentation carried out by $\mathrm{W}$. Wundt ${ }^{5}$; the role of experimentation in science was the main motive behind the sustained discussion concerning scientific method between Hobbes and Boyle, which was later analyzed by the historians Shapin and Shaffer (1985). All those cases demonstrate that the relation between theory and experiment has been the cause of analysis and reflection by scientists, historians and philosophers over the centuries.

However, the philosophical analysis of experimentation in a more systematic way is much more recent and Hacking is one of the most important figures here. Hacking points out that: "philosophers of science constantly discuss theories and representation of reality, but almost nothing about experiment, technology, or the use of knowledge to alter the world" (Hacking, 1983: p. 149), and he gives historical and contemporary examples of how theoretical scientists have gained more prestige than experimenters despite the former also experimenting and the latter performing research with theoretical models. He refers to the case of the London brothers (Fritz and Heinz) who were physicists and worked as a team: Fritz as the theoretician and Heinz the experimenter; but if Fritz could dedicate himself to theory it was only because Heinz provided him with research techniques. However, when it came to an entry in the "Dictionary of Scientific Biography” Fritz got in but Heinz did not.

Hacking's position, however, despite some of his claims and his clear interest in supporting the importance of the role of experimentation, cannot be seen as a mere reverse of TT, as the following quote clearly demonstrates:

Thus I make no claim that experimental work could exist independently of theory. That would be the blind work of those whom Bacon mocked as "mere empirics". It remains the case, however, that much truly fundamental research precedes any relevant theory whatsoever (Hacking, 1983: p. 158).

Hacking's conception of the relation between theory and experiment is reflected clearly in the metaphor of ants, spiders and bees:

Bacon: The men of experiment are like the ant; they only

${ }^{4} \mathrm{I}$ understand experimentation in a broad sense; it covers what happens in a laboratory as well as carrying out a survey or performing a psychological study. It is beyond the scope of this paper to delve into what is understood by experimentation in the different sciences from physics to sociology, but I take it that some kind of experimentation is performed in all empirical sciences.

${ }^{5} \mathrm{~W}$. Wundt is considered to be the father of experimental psychology. collect and use; the reasoners resemble spiders, who make cobwebs out of their own substance. But the bee takes a middle course; it gathers material from the flowers of the garden and the field, but transforms and digests it by a power of its own (Hacking, 1983: p. 247).

Hacking: Science must be like the bee, with the talents of both ant and spider, but able to do more, that is digest and interpret both experiments and speculation (Hacking, 1983: p. 261).

At no time did Hacking intend to base his proposal on an appeal to the cognitive sciences. However, some of his ideas could well be compared to the concept of interactive vision. Along these lines, we can interpret the step from representing to intervening as what it meant in the cognitive sciences to move from pure vision to interactive vision.

That is the first lesson: you learn to see through a microscope by doing, not just by looking. (...) new ways of seeing, acquired after infancy, involve learning by doing, not just passive looking (Hacking, 1983: p. 189).

The fact that the majority of his followers have linked TE to historicist and sociological positions more than cognitive ones, has not helped in considering him as an important figure in a philosophy of science more in tune with the new cognitive models.

Once interactive vision and the main proposals of TE have been analyzed, we can conclude that the former, together with motor cognition, provides empirical support for TE. Hacking's statements demonstrate the confluence of experiment and theory in scientific practice, and are supported by the cognitive models mentioned.

\section{Symbolic Representation versus Motor Representation}

The question of how to represent knowledge has always been a central issue in the philosophy of science. Contributions by many philosophers consist of clarifying which categories best represent the phenomena we aim to explain. All the analysis concerning concepts, law, theories and models of explanation constitute different forms of representation, although there has been no agreement as to which of the categories constitutes the basic units of representation; which for the classic conception, coinciding with the so-called "linguistic turn", were the propositional statements that were used to formulate theories. Also, proposals from the historicist period with T. Kuhn (paradigms), I. Lakatos (research programs) and L. Laudan (research traditions), among others, are forms of representing scientific knowledge. Representativity has even sometimes been a demarcation criterion between science and art; a requirement for the former but not necessarily so for the latter. In summary, representativity is not questioned, although which are the best ways to achieve it is arguable.

In the cognitive sciences, the traditional perspective with respect to representation, under the influence of the analytic tradition in the philosophy of language, maintains that concepts are by nature symbolic representations and they can be reduced to symbolic computation. This perspective entails a view of action according to which it is the end result of a process that starts with the analysis of sense data, incorporates the results of decision processes, and ends with responses (actions) to stimuli 
generated internally or externally.

Since the 1990s, anti-representationalist approaches have had an important impact. Timothy van Gelder is a good representative of this approach. In his paper "What might cognition be if not computation" (1995) he maintains that cognitive systems are dynamic systems that exhibit high degrees of coupling in the sense that any variable is changing all the time and all the pairs of variables are, directly or indirectly, mutually determining the forms of the changes of the others. For van Gelder, "the post-Cartesian agent manages to cope with the world without necessary representing it” (van Gelder, 1995: p. 381). Van Gelder's claims have been widely contested, as in the case of P. Martínez-Freire, among many others, who considers that the non-representational approaches pose problems for our understanding of cognition, since "we can accept that the human brain is a dynamic system, but its cognitive functioning as such requires representations and not simple coupling to the environment” (Martínez-Freire, 2007: p. 126). It has become evident after research in the cognitive sciences over the last few decades that symbolic representation is not the most suitable way to represent knowledge; in contrast to this, there are at least two alternatives: one is non-representational models; the other is to form a new idea of representation.

There are some contributions to this second alternative that I consider to be particularly important for the aim of this work. On the one hand, there are those related in some way to the motor system; and, on the other, those that place the emphasis on forms of representation that are linked to material anchoring. From the first, I will consider: the proposal by V. Gallese (2000) regarding "motor representations" for which the work of Rizzolatti and Sinigaglia concerning the motor system is particularly relevant; the analysis of concepts as basic categories by V. Gallese and G. Lakoff (2005); and the study of motor cognition by M. Jeannerod (2006). As examples of the second type, I will consider the contribution of M. Alac and E. Hutchins (2004) for whom the use of different material anchors, including the body itself, constitute forms of representation that go beyond the linguistic.

As well as the way the issue of representation has been tackled from the philosophy of science and from the cognitive sciences, we are going to see to what extent it is possible to combine the representativity of knowledge with cognitive models in keeping with the current state of research in the cognitive sciences. On the one hand, we can say that symbolic representation suits TT well, both focus on theory; but for a philosophy of scientific practice, which aims to encompass the whole of scientific activity and, consequently, experimentation plays an important role, symbolic representation does not seem to be the best suited. However, neither does the anti-representationalist approach seem to work as a model of science whose objective is to gain knowledge of the natural and social world and use it to achieve our human goals. Therefore, it is important to examine those cognitive models that are not anti-representationalist but which, at the same time, are not limited to symbolic representation. In fact, what underlies all the proposals that without being anti-representationalist can account for scientific practice and experimentation, beyond theoretical models, is the connection between representation and action, which leads to some form of motor representation.

Gallese relates representation and action, reconciling some of the different pronouncements regarding intentionality from a neurobiological perspective. According to Gallese "the so- called "motor functions" of the nervous system not only provide the means to control and execute action but also to represent it", and thereby: "action control and action representation become two sides of the same coin” (Gallese, 2000: p. 23). The basis that Gallese relies on for support are the results of neuroscience research, particularly that carried out by Rizzolatti and Sinigaglia.

Moreover, on adding goals to movement, the results are actions. The consequence of this is that, if up until recently the motor system was conceived of as a simple controller of movement, the most recent research indicates that the motor system controls actions. We may ask what it is that really constitutes the meaning of an observed and internally represented object; and the answer is not a purely pictorial description of its shape, size and color, but above all its intentional value. Therefore, as Gallese says, "objects acquire their full meaning only to the extent that they constitute one of the poles of the dyadic dynamic relation with the acting subject, who, in turn, constitutes the second pole of this relationship" (Gallese, 2000: p. 34). So we can say that motor representations allow us to unify representational models and dynamic models.

Another way to address representation is through simulation. The question is whether there is any way to relate simulation to a representation of action. Along these lines, Gallese (2003) indicates that imagination, as a cognitive phenomenon, can be equivalent to simulation, which leads us to see imagination as a mental simulation of action or perception.

The proposal by Gallese and Lakoff (2005) concerns the representation of knowledge through its most basic categories: concepts constitute a referent for the connection between representation and action. In this way, their objective is: "to provide a testable embodied theory of concepts, based on the results of research in neuroscience, neural computation, and cognitive linguistics, capable of reconciling both concrete and abstract concepts within a unified framework" (Gallese \& Lakoff, 2005: p. 3).

The classic theory of categorization presumes that categories form a hierarchy-from bottom to top-and that there is nothing special in the middle. Gallese and Lakoff (2005) put forward two examples to demonstrate the role of what Rosch (1994) calls "basic-level categories" and their importance for an embodied theory of concepts. Let us suppose that we have two sets of concepts that go from the most general to the most specific: furniture/chair/folding chair and vehicle/car/sports car. Chair and car are special because we have motor programs to interact with those objects, but not with furniture or vehicles in general. Therefore, the categorization is embodied precisely because of our interactions, and not only because of the objective properties of the objects.

According to Gallese and Lakoff, there is a testable empirical base for this theory that consists of the claim that: "the same circuitry that can move the body and structure perceptions, also structures abstract thought” (Gallese \& Lakoff, 2005: p. 17). In fact, at the core of this theory is the assumption that there are no specialized brain circuits for concepts in general or for abstract concepts in particular. The consequence that we can derive is that concepts are also connected to actions and we can represent objects to the extent that we interact with them through motor cognition.

When we talk of motor cognition we cannot but mention Jeannerod (2006), whose work allows us to maintain the representativity of knowledge without ignoring the influence of con- 
textual factors. As in the case of Gallese, he starts from the representation of action, and says that: "representing an action and executing it are functionally equivalent” (Jeannerod, 2006: p. 41). However, Jeannerod tackles an issue that is particularly important for scientific practice: "the degree of consciousness involved in a given action, and what are the factors and the constraints for an action to be conscious or not." (Jeannerod, 2006: p. 45) That is, an action can be conscious or not; and for it to be conscious, it is necessary to be conscious of the end that is being pursued, of how it will be carried out and of who will perform it. In short, the ends are key to the consciousness of an action.

Continuing with the relation between representation and action, Jeannerod tells us: "The representation and the execution of an action are part of a continuum, such that the representation can eventually become an executed action" (Jeannerod, 2006: p. 63). Furthermore, as W. Prinz points out: "there appears to be no support for the folk psychology notion that the act follows the will, in the sense that physical action is caused by mental events that precede them and to which we have privileged access” (Prinz, 2003: p. 26).

At the same time, Jeannerod links action to motor cognition:

Assuming that action representations are the core of motor cognition means that the objective of a study of motor cognition is to understand the content of these representations (Jeannerod, 2006: p. 165).

Generally speaking, a motor representation can be conceived as a structure that anticipates interactions with the environment: it directs movements and exploratory activities to the external world, thus making more information available (Jeannerod, 2006: p. 168).

From all these references, it is easy to conclude that it is not necessary to abandon the representativity of knowledge in order to achieve a philosophy of science in consonance with current cognitive models.

Although it is not directly linked to motor action, the proposal of Alac and Hutchins (2004) does constitute an alternative to symbolic representation. In their proposal, representation does not need to be limited to propositional statements. As a consequence, language (natural or mathematical) is not the only instrument for the representation and transmission of knowledge (although it does play an important role).

Alan and Hutchins study the cognitive processes that take place in the interpretation of images. To that end they analyze the interpretation of magnetic resonance images to see how both experts and novices use a series of semiotic resources. They manage to turn the representations of experimental data that at first just appear messy, into organized data and significant phenomena through the use of gestures, language and material structures distributed about the research spaces. This also indicates that scientific knowledge (that is, the capacity to see certain natural phenomena represented, specifically and spatially) is achieved gradually through the use of dynamic processes of the imagination.

In the proposal of Alan and Hutchins the alternative to symbolic representation follows the idea that representation can move beyond propositional language. The material basis, including both the technology and the body itself via gestures, constitutes different ways of representing the concepts that that the agents wish to transmit. The use of gestures, attributing them a particularly important role, brings me to think of a manifestation of "embodied and embedded cognition"; the body constitutes one of the elements that make up meaning.

One way or another, in all these proposals there is an attempt to build a bridge between perception and action and, as a consequence, for representation not to be of something static, but of something dynamic. Therefore, the characteristics of motor representation, of action as a whole, have very little to do with the classic symbolic representations that the anti-representationalists question.

\section{Experimental Traditions Compared to Motor Representations}

We still have to consider how TE are seen from these new representation proposals and decide which of the possible relations between TE and models of interactive vision comes out on top.

Hacking suggests two, to a certain extent mutually exclusive, ways to address scientific knowledge: representation and intervention. Although he does not explicitly say so, for Hacking moving from TT to TE involves the form of expressing scientific knowledge being through intervention and not representation. This could be the reason why, when one looks for precedents of an alternative to a philosophy of science based on symbolic representations, Hacking is rarely cited; rather phenomenologists such as Husserl and Merleau-Ponty, and pragmatists such as James, Dewey and Mead are usually higher up the list. The reason is that Hacking considers that placing experimentation at the center of scientific research means abandoning representation and that is because he cannot call upon motor representation. What Hacking did not conceive of is "representation of intervention". Therefore, the question is whether motor representation makes it possible to unite representation and intervention.

After all we have seen concerning motor representation that has arisen from the cognitive sciences, it seems clear that such a conjunction is possible; but we need to see in what way. On the one hand, intervention presumes action, that is, movement plus ends. On the other, experimentation implies imagining performance in the laboratory, or in any other place or circumstance where research is carried out. As we have seen above, according to Gallese, when we imagine an action, we simulate it and in a certain way we represent it.

The objection could be made that from the perspective of a theoretical philosophy, belonging to TT, scientists also program performance in the laboratory but the fundamental difference is the type of scheme (hierarchical or reticular) that underlies scientific practice, and which has consequences for the roles that theory and experimentation are allocated. It could also be objected that the results of scientific research are the same and that there is no reason why they should vary as a function of whether the scheme is hierarchical or reticular. However, there is a series of philosophical questions for which the type of scheme we start from is important.

- Only from an aprioristic, and therefore non-naturalized, philosophy of science could it be considered unimportant whether the models of science fit as closely as possible the way in which humans commonly process, represent and act in our environment. Therefore, if the reticular scheme better reflects how we humans act, a naturalized philosophy cannot ignore it. 
- One of the central ideas of interactive vision is that what we see is not a fully elaborated representation of the visual scene, but what we perceive is influenced by the goals we pursue. From this we can conclude that it is important that what we imagine is the action because it will provide us with an appropriate idea of what is to be done in the laboratory. That is, scientists who enter the laboratory with only a representation of the theory will then have to consider how to implement it through experimentation. From the cognitive point of view, that requires more time and surely more effort than if they enter with a representation of the set of the actions that they need to perform. The objection could be raised that scientists already behave in this way. Perhaps they do; but then we agree that a philosophy of science whose conception is theoretical and which responds to what is known as TT, does not reflect what really happens in laboratories and does not take into account the cognitive processes of the agents involved in scientific practice.

- From a historical perspective, in the case of scientists who concentrated on experimentation, it is clear that they imagined a representation of the action that they were going to perform. It is not the case that they had no theoretical framework and where acting completely in the dark, but their primary task was to simulate action with specific ends; which could be to discover a new substance, a new particle, a new molecular process, or a new form of social organization.

- The cognitive element has been practically non-existent in the work of the historians and philosophers I refer to (Hacking, Galison, Pickering, Gooding, Pinch and Schaffer, Martinez, and Ordoñez and Ferreirós). However, their vision of scientific practice, centered on experimentation, fits in with the form of cognition of motor representations.

- It is beyond the aim of this work to address the idea of motor representation in design sciences, but it should be pointed out that, given that in those sciences action constitutes their raison d'être, it is difficult to apply models of science that were conceived for descriptive sciences, focused on theory. Therefore, it is reasonable to conclude that motor representations would be a good way to approach sciences whose objective is to transform the world and not only to describe it.

\section{Conclusion}

Of the three possibilities that I suggest at the beginning of this paper, we could say that, on the one hand, TT and pure vision, and on the other, TE and interactive vision, are mutually reinforcing. In this work I have particularly focused on whether the conception that is emerging in the philosophy of science in ET is supported by the cognitive models that address motor cognition, and that we could see as one of the consequences of the interactive and dynamic vision proposed by Churchland, Ramachandran and Sejnowski in 1994.

The idea of interactive vision as a system that is integrated with other functions also constitutes an analogous model for a philosophy of scientific practice, since this is also constituted of different elements. Pure vision can be seen as the equivalent of a philosophy of the science centered on the product, as logical empiricism was. However, the idea of approaching science as scientific activity or practice is not just a nominative question, rather it responds to the objective of approaching science from different points of view, globally, and thereby seeing it as consisting of various different functions; although at a specific moment, we can concentrate on one particular aspect.

Anti-representationalist approaches are a handicap for the cognitive view in the philosophy of science since, although they are an alternative to the symbolic paradigm of information processing, they bring into question one of the essential characteristics of science: its function of representing knowledge. In contrast, motor representations, backed up by the empirical results of neuroscience, allow us to maintain the idea of representation without abandoning contextual aspects of scientific practice that go beyond the purely theoretical.

\section{REFERENCES}

Alac, M., \& Hutchins, E. (2004). I see what you are saying: Action as cognition in fMRI brain mapping practice. Journal of Cognition and Culture, 4, 629-661. doi:10.1163/1568537042484977

Ballard, D. H., Hayhoe, M. M., \& Pook, P. K. (1995). Deictic codes for the embodiment of cognition. Rochester: University of Rochester, National Resource Laboratory for the Study of Brain and Behavior.

Clark, A. (2003). Natural-born cyborgs. Minds, technologies, and the future of human intelligence. Oxford: Oxford University Press.

Churchland, P. M. (1989). A neurocomputational perspective. The nature of mind and the structure of science. Cambridge, MA: The MIT Press.

Churchland, P. S., Ramachandran, V. S., \& Sejnowski, T. J. (1994). A critique of pure vision. In C. Koch (Ed.), Large-scale neural theories of the brain. Cambridge, MA: The MIT Press.

D’Andrade, R. (1989). Culturally based reasoning. In A. Gellatly, D. Rogersy, \& J. A. Sloboda (Eds.), Cognition and social worlds. Oxford: Oxford University Press.

Estany, A. (1999). Vida, muerte y resurrección de la conciencia. Análisis filosófico de las revoluciones científicas en la psicología contemporánea. Barcelona: Paidós.

Estany, A. (2001). The theory-laden thesis of observation in the light of cognitive psychology. Philosophy of Science, 68, 203-217. doi:10.1086/392873

Ferreirós, J., \& Ordóñez, J. (2002). Hacia una filosofía de la experimentación. Crítica, Revista Iberoamericana de Filosofía, 34, 47-86.

Galison, P. L. (1987). How experiments end. Chicago, IL: University of Chicago Press.

Gallese, V. (2000). The inner sense of action. agency and motor representations. Journal of Consciousness Studies, 7, 23-40.

Gallese, V., \& Lakoff, G. (2005). The brain's concepts: The role of the sensory-motor system in conceptual knowledge. Cognitive Neuropsychology, 22, 455-479. doi:10.1080/02643290442000310

Gardner, H. (1987). The mind's new science. A history of the cognitive revolution. New York: BasicBooks Harper Collins Publishers.

Giere, R. (1988). Explaining science. A cognitive approach. Chicago, IL: University of Chicago Press. doi:10.7208/chicago/9780226292038.001.0001

Giere, R. (1992). Cognitive models of science. Minneapolis, MN: University of Minnesota Press.

Goldman, A. (1986). Epistemology and cognition. Cambridge, MA: Harvard University Press.

Gooding, D., Pinch, T., \& Shaffer, S. (1989). The uses of experiment: Studies in the natural sciences. Cambridge: Cambridge University Press.

Hacking, I. (1983). Representing and intervening. Introductory topics in the philosophy of natural science. New York: Cambridge University Press. doi:10.1017/CBO9780511814563

Hempel, C. G. (1966). Philosophy of natural science. Englewood Cliffs, NJ: Prentice-Hall.

Hutchins, E. (1995). Cognition in the wild. Cambridge, MA: The MIT Press.

Iglesias, M. (2004). El giro hacia la práctica en filosofía de la ciencia: una nueva perspectiva de la actividad experimental. Revista de Cien- 


\section{A. ESTANY}

cias Humanas y Sociales, 20, 98-119.

Jeannerod, M. (2006). Motor cognition. What actions tell the self. Oxford: Oxford University Press.

doi:10.1093/acprof:oso/9780198569657.001.0001

Johnson-Lair, P. N. (1983). Mental models: Towards a cognitive science of language, inference and conciousness. Cambridge, MASS: Harvard University Press.

Laudan, L. (1984). Science and values. The aims of science and their role in scientific debate. Los Angeles, CA: University of California Press.

Marr, D. (1982). Vision: A computational investigation into the human representation and processing of visual information. San Francisco, CA: W.H. Freeman.

Martínez, S. (1995). Una respuesta al desafío de Campbell: La evolución de técnicas y fenómenos en las tradiciones experimentales. Diánoia. Anuario de Filosofía, Instituto de Investigaciones Filosóficas, 9-31.

Martínez, S. (2006). The heuristic structure of scientific practices: A non-reductionistic account of practices as heuristic structure. Chinese Studies in the Philosophy of Science, 53, 1-23.

Martínez-Freire, P. (2007). La importancia del conocimiento. Filosofía y ciencias cognitivas. A Coruña: Netbiblo.

doi:10.4272/978-84-9745-172-7

Ordóñez, J., \& Ferreirós, J. (2002). Hacia una filosofía de la experimentación. Critica, Revista Hispanoamericana de Filosofía, 34, 47-
86.

Pickering, A. (1995). The mangle of practice. Chicago, IL: The University of Chicago Press. doi:10.7208/chicago/9780226668253.001.0001

Popper, K. (2002). Logic of scientific discovery. London/New York: Routledge Classics.

Rheinberger, H.-J. (1997). Toward a history of epistemic things. Synthesizing proteins in the test tube. Stanford: Stanford University Press.

Rizzolatti, G., \& Sinigaglia, C. (2006). Mirrors in the brain: How our minds share actions, emotions, and experience. Oxford: Oxford University Press.

Rosch, E. (1994). Categorization. In V. S. Ramachanadran (Ed.), The encyclopedia of human behavior. San Diego, CA: Academia Press.

Shapin, S., \& Schaffer, S. (1985). Leviathan and the air-pump: Hobbes, boyle, and the experimental life. Princeton: Princeton University Press.

Slaney, M. (1998). A critique of pure audition. In D. F. Rosenthal, \& H. G. Okuno (Eds.), Computational auditory scene analysis. Mahwah, NJ: Lawrence Erlbaum Associates.

Van Gelder, T. (1995). What might cognition be if not computation. The Journal of Philosophy, 92, 345-381. doi: $10.2307 / 2941061$

Wolfe, A. B. (1924). Functional economics. In R. G. Tugwell (Ed.), The trend of economics. New York: Alfred A. Knopf. 